\title{
What Executives Can Learn From Frank Serpico
}

Francis Petit, Fordham University, USA

\begin{abstract}
The purpose of this research is to determine what executives can learn from Francesco Vincent Serpico (aka Frank Serpico). To determine this information, a historical study of Frank Serpico's career was conducted with the hopes of uncovering key takeaways and learning points for executives. The main findings of this study indicate that there are various lessons that executives can learn from the Frank Serpico journey as the first New York City Police Officer who not only reported corruption among its ranks and who voluntarily testified in court, but who also, as a result of his actions, subsequently forever changed the pervasive culture of corruption within the department. The results of this exploratory study can potentially ignite increased research on the "Frank Serpico Effect" and what executives and corporate America can learn from a Police Officer from Brooklyn.
\end{abstract}

Keywords: Frank Serpico; New York Police Department; Corruption; Graft; Executive Development

\section{INTRODUCTION}

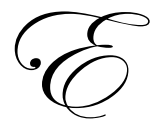

xecutives and professionals in business are always seeking that edge. Whether it be enrolling in a graduate degree program (i.e. MBA), participating in a non-degree executive or continuing education course, or reading vociferously new theories of business strategy, many professionals in the workforce are actively seeking that differential.

With this as a backdrop, the purpose of this research is to study the life of Mr. Francesco Vincent Serpico (aka Frank Serpico) to see if there exits any lessons or takeaways that would benefit executives and corporate America as a whole.

As a background, Frank Serpico, according to his official website, (http://www.frankserpico.com/), was born on April 14, 1936, in Brooklyn, New York, to first generation Italian parents. At the age of 18, Frank Serpico enrolled in the United States Army and served two years in Korea. At the age of 23, Frank Serpico joined the New York Police Department (NYPD) on September 11, 1959, and served until 1972. He left the NYPD after receiving the "Medal of Honor", the highest award given by the Department (Maas, 1973 and 1997).

Yet what occurred during the 13 years of Frank Serpico's tenure as a New York City Police Officer was certainly where he not only became famous, but also forever made his mark. More specifically, Frank Serpico was the first officer in the history of the NYPD who not only reported corruption among its ranks, but who also voluntarily stepped forward and testified about it within a court of law (Maas, 1973, 1997, p. 13). This occurred after a 4-year journey in which Frank Serpico attempted to get action from high-level police and political officials regarding the existing corruption risking personal discovery at any moment from the unethical police officers he worked with each and every day. Finally after not making any significant progress with this strategy and after a "harrowing interrogation by U.S. customs officials upon returning from a European vacation", Frank Serpico went public with his story with a reporter from The New York Times. The article appeared in this periodical in April 1970 and led to a series of events including the formation of the Knapp Commission, led by Whittman Knapp. Its charge was to investigate the pervasive problem of corruption within the NYPD. 
In addition, as a result of this article, other events occurred, including the abrupt resignation of the Police Commissioner, a mass exodus of high level police leadership, new procedures and processes, additional indictments, and increased accountability of police commanders regarding corruption within the unit (Maas, 1973 and 1997, p. 14).

As indicated previously, Frank Serpico testified in court regarding this corruption. It should also be noted that on February 3, 1971, Frank Serpico was shot in the face in the line of duty during a "buy and bust" drug operation in Brooklyn, New York. While it could not proven, there are theories that state that Frank Serpico was "set up" by his fellow police officers as a result of his willingness to report the corruption within the Department (Maas, 1973, 1997). It should also be noted that Frank Serpico's original intent was not to be a "whistleblower" within the Department, but rather all he wanted to do initially was to be a Police Officer and not accept any bribes or favors as a result of his professional position within the community (Maas, 1973, 1997). Lastly, it should be noted that a feature film titled Serpico was released in 1973. It starred Al Pacino and was directed by Sydney Lumet.

Since leaving the NYPD, Frank Serpico led a life of anonymity within Europe and upstate New York (Kilgannon, January 22, 2010). This was done for his own protection purposes as former police officers, their families and organized crime organizations held extreme anger and resentment towards him (Kilgannon, January 22, 2010).

\section{LITERATURE REVIEW}

Very little has been written about Frank Serpico from an academic perspective. One reason that may explain this occurrence, as stated earlier, is that ever since Frank Serpico left the NYPD in 1972, he lived a life of extreme anonymity within Europe and also in upstate New York. One hypothesis as to why Frank Serpico selected this type of lifestyle is that ever since coming forward and testifying about corruption within the NYPD, there were (and are) many individuals that have extreme anger and resentment towards him, including former police officers and their families, as well as organized crime organizations. As a result, from a research perspective, it has been very difficult to track him down and interview him. Therefore, his elusive and incognito approach to life post his NYPD career has potentially led to very little written about Frank Serpico from an academic perspective.

However, there are some items that need to be mentioned. In 1973, Peter Maas wrote Seprico (Viking Press) which was a thorough and entailed account of the law enforcement career of Frank Serpico and everything he experienced within the "corruptive force". The book was also the impetus for the 1973 feature film titled Serpico staring Al Pacino and directed by Sydney Lumet. Frank Serpico, according to the "Afterward" he wrote in the second edition of Serpico (Perennial, 1997), indicated that he did spend time with Peter Maas in the development of the book as well as actor Al Pacino who played Serpico in the feature film. However, Frank Serpico did not spend much time at all on the movie set as he indicated he "wasn't really wanted there." He did, however, collaborate on the development of the screenplay (Maas, 1973, 1997, p. 399).

It should also be noted that much has been written about the Knapp Commission and its findings. More specifically, the Knapp Commission, named for its Chairman, Whitman Knapp, began its investigation on corruption within the NYPD in June 1970. The Knapp Commission, which is also known as the "Commission to Investigate Alleged Police Corruption", began its public hearings in October 1971 (Chin, 1997). This Commission, which formed in April 1970 by Mayor John V. Lindsay, was a result of the publically generated corruption revelations ignited by Frank Serpico (Barker, 1978).

The final report of the Knapp Commission was generated in December 1972. The Commission not only reported widespread corruption within the NYPD, but also made recommendations, including increased accountability by commanders, increased presence of the Internal Affairs Division and undercover informants within all precincts, improved screening and selection processes of police officers, as well as an overall change in the police attitude and culture (Braziller, 1972).

The Knapp Commission also identified two types of corrupt police officers. The first type is known as "Grass Eaters" which can be associated to a high percentage of police officers. "Grass Eaters" accept gratuities of 
small amounts (i.e. money, side jobs, etc.) and do so to prove their loyalty to the Police Brotherhood. The second type is known as "Meat Eaters" who spend a majority of their time trying to exploit for financial gain. "Meat Eaters" oftentimes obtain financial gain through criminals, such as drug dealers and pimps. They justify their actions as they consider these criminals worthless citizens who deserve this type of treatment. "Meat Eaters" also feel a sense of entitlement towards these rewards (Braziller, 1972).

It should also be noted that Frank Serpico does lecture, on occasion, to different organizations regarding police corruption and is quoted periodically regarding specific police corruption cases. There also exists scattered periodical articles on Frank Serpico.

This summarizes the literature on Frank Serpico and his impact. Overall, the goal of this research is to not necessarily readdress the impact of Frank Serpico on police corruption within the NYPD and beyond, but rather, the goal is to illustrate what executives and professionals can learn from Frank Serpico and what traits can be transferred to any industry.

\section{METHODOLOGY}

An in depth historical analysis of the career of Frank Serpico was conducted. The goal of this research was to determine if there were any themes that emerged which would benefit the careers of professionals and executives. Conclusions were formulated and presented within this research.

\section{FINDINGS}

Four themes emerged as a result of conducting this research. Below please find these themes and the reasons why executives would potentially benefit from them.

\section{THEME \#1 - UPHOLDING ONE'S MORAL COMPASS}

Frank Serpico is best known for upholding his moral compass in a very dangerous, difficult and tumultuous environment when he was a New York City Police Officer. At the time of his service, especially within the "Plain clothes Division", corruption and graft where not only prevalent, but also a standard mode of operation among many in the unit. It was not uncommon that police officers would receive anywhere from $\$ 200$ to $\$ 1,000$ or more per month in cash as a result of these illegal operating procedures (Maas, 1974, 1997).

At first, Frank Serpico did not seek out high level police authority to rid this type of behavior. He simply did not accept any of these monthly payments as he was abiding by his moral compass. As time passed, an increased number of police officers within his specific division were alerted to the fact that Frank Serpico was not a participant in this monthly kickback scheme. His fellow officers, as a result of their insecurity, became suspicious of Frank Serpico and pressured him to be a participant. Frank Serpico's ferocious persistence in not participating and his strong abidance to his moral compass created an unhealthy and even dangerous work environment for himself. This continued during the second half of his police career (Maas, 1974, 1997).

This notion is further reinforced and can be seen on a November 5, 2010, address that Frank Serpico gave to the Fordham University Executive MBA students in New York City (http://www.youtube.com/watch?v=SvIiU95RS Y). In it, he discusses not only the abidance of the moral compass, but also the importance of formulating it during one's youth as it is virtually impossible to develop it as an adult. It was also apparent from his address that Frank Serpico was an individual who stood by the mission of the New York Police Department and would not sway or violate that mission at any cost.

Consequently, Frank Serpico was not only an ethical police officer and professional, but also wholeheartedly lived by the central tenants of his organizations. All executives and professionals can learn from Frank Serpico's actions and can also benefit from these attributes. 


\section{THEME \#2 - THE INNOVATIVE MINDSET}

Organizations, by their nature, stifle any form of creative and innovative thinking. The average lifespan of a CEO in any organization is less than six years and most will not risk a new-to-world innovation when earnings have to be reported every 90 days (Kuczmarski, 2005). Innovation is a time consuming initiative and failure, no doubt, is part of the process. However, CEO's tend to be more risk averse when it comes to innovation given the urgency to illustrate short-term improvement in financial performance. As a result, most organizations lack any type of innovative mindset within its culture given it must be a top-down approach (Kuczmarski, 2005).

With this as a backdrop, one would assume an organization, such as the NYPD, would also lack this innovative mindset given its size and bureaucratic nature. However, Frank Serpico, as a New York City Police Officer, certainly illustrated his innovative mindset in how he approached his work. This was also apparent in his address to the Fordham Executive MBA students on November 5, 2010.

More specifically, Frank Serpico was an innovator within his profession. His Bohemian and hippie-like appearance as a plain clothes police officer was an extremely interesting method to fight crime at that time. Add to this the many costumes he utilized on the job (i.e. drug dealer/user, rabbi, etc.) and what you get is a creative "outside the box" thinker who was not afraid to experiment, and even fail, in order to increase effectiveness. Frank Serpico, by his actions, certainly had an innovative mindset in a bureaucratic, "overtime driven" culture. Such a mindset should be noted by all executives across any industry.

\section{THEME \#3 - THE POWER OF UNIQUENESS}

In addition to upholding his moral compass and for his innovative mindset, Frank Serpico also brought uniqueness to the New York Police Department. Unlike the stereotypical police officer during that era, Frank Serpico not only learned multiple languages and was a huge fan of opera, but he also had an intense cultural mindset. His frame of reference and diversity of thought was also clearly illustrated in his address to the Fordham Executive MBA students.

Oftentimes in business, disagreements and clashing perspectives, if openly heard, can raise the dialogue to a new level, creating solutions for the best interest of the enterprise. This can only occur if you assemble the best group of people together with no vested interest other than the organization in question. These individuals will passionately discuss issues and potential solutions looking at it from all angles. Their goal is simple - to move the organization forward. As long as the "right individuals" are "on the bus", the entire organization will benefit (Collins, 2001). In the case of Frank Serpico, it is apparent that his uniqueness had a positive impact on the NYPD as he questioned established norms and tried to find a better way to operate. As a result, executives should not only take note of the Frank Serpico story, but also embrace the differences of the workforce for these reasons.

\section{THEME \#4 - THE POWER OF VOCATION}

Frank Serpico discovered his vocation at a young age and that was to be a New York City Police Officer. Throughout his career in the NYPD, it was apparent that his vocation was pursued with passion, intensity and integrity. Discovering one's vocation in life is oftentimes not an easy task. In a world that has become increasingly driven by wealth and material possessions, it is apparent that these goals are increasingly dictating personal planning and decision making. It is almost as if society has become "slaves to prosperity" as opposed to obtaining personal happiness and contentment (Lowney, 2009).

Frank Serpico was first and foremost a New York City Police Officer. This was evident from his address to the Fordham University Executive MBA students on November 5, 2010. Police work was Frank Serpico's passion and vocation. It defined who he was and who he is today. His passion and vocation has changed his life for better and for worse.

In a world where professional decisions are increasingly aligned with wealth and instant gratification, it was apparent that Frank Serpico did not follow this routine as this could have been achieved through corrupt and 
unethical behavior. Rather, Frank Serpico understood his vocation and did not violate it at any cost for short-term monetary rewards. Executives should, once again, take note on the power of passion and vocation in the workplace. Such a combination can lead to positive results for any organization.

\section{CONCLUSION}

Although it has been over 40 years since Frank Serpico was shot in the line of duty, the lessons he has illustrated from his actions are not only powerful, but can also be transferred to any profession within any industry. These lessons include upholding one's moral compass, the innovative mindset, the power of uniqueness, and the power of vocation. While additional research needs to be conducted, the results of this exploratory study can potentially spark increased interest in the "Frank Serpico Effect" and the overall impact of this Police Officer from Brooklyn.

\section{AUTHOR INFORMATION}

Francis Petit is the Associate Dean for Executive MBA Programs at Fordham University's Graduate School of Business Administration. He also serves as an Adjunct Associate Professor of Marketing at Fordham University. He holds a Doctorate in Economics and Education from Columbia University. It should be noted that Frank Serpico was a guest speaker at the Fordham University Executive MBA Program on November 5, $2010 . \quad$ E-mail: petit@fordham.edu

\section{REFERENCES}

1. Barker, T. (1978). “An Empirical Study of Police Deviance Other Than Corruption”, Journal of Police Science and Administration, 6 (3): 264-272.

2. Braziller, G. (1972). The Knapp Commission Report on Police Corruption. New York: George Braziller.

3. Chin, G. (Ed.) (1997). New York City Police Corruption Investigation Commissions, New York: William S. Hein \& Co.

4. Collins, Jim. (2001). Good to Great, HarperBusiness, New York.

5. Kilgannon, Corey. (January 22, 2010). "Serpico on Serpico", The New York Times.

6. Kuczmarski, Thomas D. (2005). Innovation: Leadership Strategies for the Competitive Advantage, Book Ends Publishing, Chicago, Illinois.

7. $\quad$ Lowney, Chris. (2009). Heroic Living, Loyola Press, Chicago, IL.

8. Maas, Peter, (1973, 1997). Serpico, Viking press / Perennial, New York. 


\section{NOTES}

